\title{
Effect of Children's Support on Depression among Older Adults Living Alone or with a Spouse: A Comparative Analysis between Urban and Rural Areas of China
}

\author{
Xiaocui Ren ${ }^{1}$ and Chen $\mathrm{Lu}^{2, *}$ \\ 1 Sino-Danish College, University of Chinese Academy of Sciences, Beijing 100190, China; \\ renxiaocui18@mails.ucas.ac.cn \\ 2 School of Public Policy and Management, University of Chinese Academy of Sciences, Beijing 100049, China \\ * Correspondence: lvchen@ucas.ac.cn
}

\section{check for} updates

Citation: Ren, X.; Lu, C. Effect of Children's Support on Depression among Older Adults Living Alone or with a Spouse: A Comparative Analysis between Urban and Rural Areas of China. Sustainability 2021, 13, 6315. https://doi.org/10.3390/ su13116315

\section{Academic Editors: Giuseppe}

Battaglia, Marina Butovskaya and José Carmelo Adsuar Sala

Received: 27 March 2021

Accepted: 31 May 2021

Published: 2 June 2021

Publisher's Note: MDPI stays neutral with regard to jurisdictional claims in published maps and institutional affiliations.

Copyright: (c) 2021 by the authors. Licensee MDPI, Basel, Switzerland. This article is an open access article distributed under the terms and conditions of the Creative Commons Attribution (CC BY) license (https:/ / creativecommons.org/licenses/by/ $4.0 /)$.

\begin{abstract}
Against the backdrop of rapid urbanization and severe population aging, older adults living alone or with a spouse in China have become a special and vulnerable group that deserve more research attention. Based on a national sample of 3886 older adults ( $\geq 60$ years old) living alone or with a spouse, we used multiple linear regression models to investigate the effect of children's support on depression among older adults living alone or with a spouse in China. A comparative analysis was conducted to examine the differences between urban and rural areas. The results indicated that financial support from children was negatively correlated with depression among older adults living alone or with a spouse, especially in rural areas. Their children's frequency of contact also significantly alleviated depression among non-cohabiting parents in rural areas, but not for the same types of parents living in urban areas. Compared with financial support, their children's frequency of contact contributes more to decreasing depression among older adults living alone or with a spouse. The effect of their children's support on depression is comparable to that of demographic characteristics, which are usually deemed as important factors in the psychological health of older adults. Moreover, we found that the marginal effects of self-rated health and pain were significant and much higher than other control variables, especially in the urban model.
\end{abstract}

Keywords: children's support; older adults; depression; urban-rural differences; CHARLS

\section{Introduction}

China is facing severe challenges in terms of population aging. It is predicted that the older adult population will account for more than $30 \%$ of China's total population by 2050 [1]. In regard to social development, the problem of older adults will become a significant issue in the future. Since the reform and opening up, the rapid development of the economy has dramatically improved people's living standards. The Chinese government attaches more importance to the all-round development of human beings, emphasizing the coordination of psychological and physiological development. The mental health of older adults is attracting more and more attention, because depression-as one of the most prevalent psychological diseases-is very common among older adults. However, from a nationwide perspective, there are significant urban-rural differences in China when it comes to depression experienced by older adults because of the uneven societal and economic development across the country. Nearly $45 \%$ of older adults in urban areas show varying degrees of depressive symptoms, while depression in rural regions is more common and severe, accounting for about $65 \%$ [2].

Along with the changes that have occurred over time and the development of the society and the economy, other remarkable changes in the family structure and size have altered the living environment and lifestyles of older adults [3]. More older adults are living separately, away from their adult children. A lack of resources, companionship, 
and communication for older adults living alone have led to them becoming a vulnerable group with a tendency toward depression [4]. Studies have shown that intergenerational support is an important factor that affects the psychological well-being of older adults. In traditional family culture in China, older adults mainly live together with their adult children, and rely on their children's support, which has had an irreplaceable status in Chinese society for a long time [5]. However, the support systems of older parents are constantly facing new challenges. Living separately has interfered with the function of support that older adults previously received from their children and, in turn, has affected their mental health [6]. With the transformation of Chinese society, the group of older adults living alone or with a spouse (OALAWAS) has become larger; however, insufficient attention has been paid to this group thus far. Based on the above analysis, we aim to answer the following research questions in this study:

Q1: Is there an urban-rural difference in depression among OALAWAS?

Q2: How does children's support affect depression among OALAWAS?

Q3: Are there differences between rural and urban areas in terms of the effect of children's support on OALAWAS?

\section{Literature Review}

\subsection{Research on Depression among Older Adults}

Depression is a mood disorder that can harm the mental health of older adults, reduce life satisfaction, and increase the incidence of disease and suicide [7]. Studies of depression in older adults commonly use the International Classification of Diseases [8], the 15-item Geriatric Depression Scale $[9,10]$ and the Center for Epidemiological Studies Depression Scale [11] to measure the depression degree. There are many factors that affect depression among older adults, including their demographic characteristics (age, gender, marital status, etc.), physical health (chronic diseases, cancer, disability, etc.), socioeconomic status (education level, income, etc.), and social characteristics (social interaction, social support, etc.). Studies have found that the senior-aged group of older adults has the highest proportion of moderate depressive symptoms or even worse depressive symptoms [7,12]. Female older adults are more likely to be depressed than males. Moreover, unpartnered older adults, especially widows, are more at risk of experiencing depressive symptoms [13-15]. Physical health directly impacts depression among older adults, as older adults with physical illnesses or experiences (such as chronic illnesses, limited functions, or pain) tend to be more depressed $[2,16]$. Older adults with low education levels and poor self-assessed economic status are also more inclined to experience depressive symptoms [2,17].

Positive social interaction and participation are associated with lower depression scores [18]. In addition, social support is an important factor that affects the mental health of older adults. A lack of social support has been identified as a risk factor for depression in later life [7]. In the social support network of older adults, support from relatives, especially from children and spouses, plays a key role in their lives, while support from friends, neighbors, communities, and the government are of secondary importance $[19,20]$. Intergenerational support is defined as various support activities that are carried out between older parents and children, which comprises an important part of social support [21].

Moreover, living arrangements are a direct reflection of the living environments of older adults. Living arrangements affect the amount of social support that older adults receive from their families [22]. Co-residence arrangements have a positive effect on the self-rated health of older adults compared with those living alone [23]. Intergenerational co-residence is proved to be beneficial to the subjective well-being of older adults, and elders who live with their adult children are happier than those who have different living arrangements [24]. Older adults who live both with a spouse and with their adult children report superior mental health compared to those living alone [25]. Older adults living alone or with a spouse tend to have a positive link to depression [26]. Furthermore, compared to elderly couples who had a spouse, those living alone had higher blood pressure and 
more depressive symptoms [27]. Finally, the findings of other studies appear to confirm that living alone is an important factor that leads to depression among older adults $[28,29]$.

\subsection{The Impact of Intergenerational Support on Depression among Older Adults}

Intergenerational support includes both children's support for older adults and older parents' support for their children, which is a two-way reciprocal process [30]. It mainly includes financial support, represented by cash or material assistance, life care, represented by housework, and emotional support, represented by the emotional connection between older parents and their children [21,31,32].

Many studies have unanimously concluded that children's emotional support is inversely related to depression among older adults [6,33]. However, in the measurement of emotional support, scholars use different indicators and processing methods in their research. Some studies measured emotional support by the frequency of contact between older adults and their children, such as face-to-face meetings, telephone calls, text messages, emails, and social media [34-38]. Others use emotional cohesion to determine whether the emotional relationship between children and older parents is strong [33]. The above two measurement indicators consider both the content and frequency of emotional support. However, some studies only ask questions such as whether older adults receive emotional support, or how many family members are in contact with them within the space of a month [17]. Moreover, some scholars point out that the best frequency of contact to enable an emotional connection is recommended as a phone call every day and visits 2-3 times a week [39].

Financial support is mostly measured by whether older adults have received regular material or monetary help from their children in the past 12 months. Material goods include food, clothing, and other essentials $[30,31,40]$. However, the impact of children's financial support on depression among older adults is controversial. One study found that children's financial support can reduce the risk of depression in older adults, because financial assistance could improve their quality of life and older adults could obtain a sufficient sense of security [17]. Another view is that children's financial support deepens guilt and feelings of uselessness among older adults, which may lead to depression [32,41]. After retirement, older adults have difficulty in adapting to a new life and accepting the fact that they have retired. Obtaining financial support from children means that they can no longer cover their basic cost of living and become a burden to their children.

Life care is usually measured as help from children with the activities of daily life in the last 12 months $[30,31,40]$. This includes help with household tasks, such as cleaning the house, washing clothes, and personal care tasks such as bathing and dressing [31,40,42]. Some researchers have shown that obtaining life care has a positive effect on reducing depression among older adults. In particular, baseline instrumental support from their sons marginally reduced parents' depressive symptoms [41,43]. Care from children is a manifestation of filial piety, which satisfies older adults' expectations of their families. However, for older adults with physical disabilities, receiving too little or too much life care from their children can cause a high level of depression [44]. This shows that the impact of children's life care on depression among older adults varies with their physical condition.

Support from older adults for their children form part of intergenerational support, which can significantly reduce their depression levels [39]. In terms of financial support, some studies show that providing financial support to children will reduce the likelihood of depression among older adults; this is mainly because older adults may feel self-accomplishment, which will improve their personal life satisfaction [40,45]. Another view is that having to provide too much financial support to their children will increase the financial burden for older adults, because most older adults rely on only one source of income, their retirement pension, which is often relatively low. The burden of children makes older adults feel emotionally heavy and helpless, increasing their tendency toward depression. Some studies also insist that older adults providing children with an appropriate amount of housework to complete is beneficial to their mental health [46]. Taking 
care of grandchildren is the main aspect of life care provided by other adults for their children. Appropriate care behaviors enable older adults to reap their grandchildren's recognition and realize their self-worth, which is beneficial for their physical and mental health [43]. However, some studies show that older adults are suffering from cumbersome intergenerational care. Over time, this will worsen the physical health of older adults, causing increased stress and depression [47].

\subsection{Summary}

The existing literature shows that demographic characteristics, physical health, socioeconomic status, and social characteristics are closely related to depression among older adults. Since support from children plays a significant role in older adults' lives, scholars have begun to explore the effect of intergenerational support on depression among older adults. In China, intergenerational support, especially children's support for their parents, plays a critical role and has a special meaning to older adults against the backdrop of filial piety culture $[48,49]$. However, with the shrinking households and the increasing number of OALAWAS, studies on the relationship between children's support and depression levels among OALAWAS are still insufficient. First, the existing studies only showed that living arrangements and intergenerational support have an influence on depression among older adults. However, the effects of intergenerational support on depression among OALAWAS have not yet been revealed. Second, the different effects of children's support between urban and rural areas must be explored further. In China, with the disparity in the development of urban and rural areas, the living conditions of OALAWAS in urban areas are obviously different from those in rural regions. Is there a significant urban-rural difference in depression among OALAWAS across the country? Does the impact of children's support on depression among OALAWAS show that there are differences between urban and rural areas? These issues are worthy of further exploration. This study aims to discover whether depression among OALAWAS in urban areas is significantly different to that of OALAWAS in rural areas of China, as well as to analyze the relationship between children's support and depression among OALAWAS from the perspective of urban-rural differences.

\section{Materials and Methods}

\subsection{Theory and Hypothesis}

Based on the research theme and the related literature, we propose an analytical framework to assess the impact of children's support on depression among OALAWAS in urban and rural regions, as shown in Figure 1. Depression among OALAWS is influenced by many factors, and there are vast disparities in these influencing factors between urban and rural China, due to the process of rapid economic development and urbanization. The population structure differs between urban and rural areas, because a large number of the young population migrate from rural areas to urban regions. The income sources of older adults between rural areas and urban areas are also different because of the binary social welfare system in China. The lifestyle, cultural background, and inhabited environments are also different because of the distinctive modes of production and varying public service facilities provided by the government. Therefore, due to the heterogeneity in the living environment between urban and rural areas, the effect of children's support on depression among OALAWAS living in urban could be different from that in rural areas. 


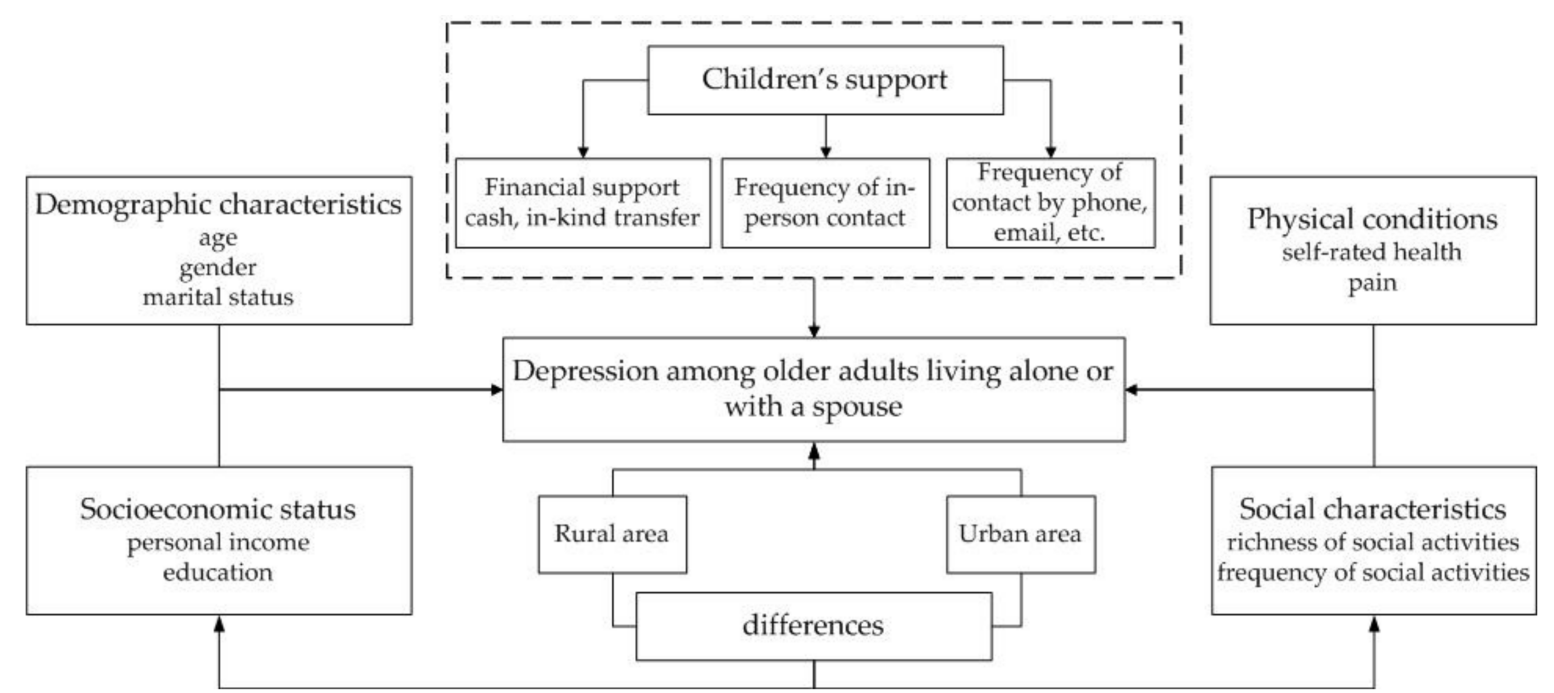

Figure 1. Analysis framework for the impact of children's support on depression among OALAWAS.

Most of the existing literature categorizes children's support into financial support, emotional support, and life care and instrumental support. Financial support is important to the mental health of OALAWAS because it can enrich the income of OALAWAS and lessen any financial stress they may be under. Financial support is usually measured by cash and in-kind transfers provided to older adults. Life care and instrumental support could help OALAWAS who struggle with heavy housework, and it is often measured by the frequency with which children have helped their parents with daily chores over the past year or past several months. Life care and instrumental support are proven to be highly related to the frequency of in-person contact and informational support [50-52]. Frequency of contact includes in-person meetings and contact by telephone, email, etc. Both methods of contact can enrich the communication between the generations. Moreover, face to face contact may not only relieve the loneliness of OALAWAS but may also lead to life care and instrumental support, which benefit the mental health of OALAWAS. In addition, contact via phone or email could provide OALAWAS with more informational support. Therefore, we assume that financial assistance from their children could improve the living conditions of OALAWAS and could reduce the possibility of depression. Moreover, children's frequency of contact could also reduce the incidence of depression among OALAWAS. As such, we propose the following hypotheses:

Hypothesis 1 (H1). Children's financial support can reduce depression among OALAWAS;

Hypothesis 1a (H1a). Children's financial support can reduce depression among OALAWAS in rural areas;

Hypothesis $\mathbf{1 b} \mathbf{( H 1 b ) . ~ C h i l d r e n ' s ~ f i n a n c i a l ~ s u p p o r t ~ c a n ~ r e d u c e ~ d e p r e s s i o n ~ a m o n g ~ O A L A W A S ~ i n ~}$ urban areas;

Hypothesis 2 (H2). Children's frequency of contact can reduce depression among OALAWAS;

Hypothesis 2a (H2a). Children's frequency of contact can reduce depression among OALAWAS in rural areas;

Hypothesis 2a1 (H2a1). The higher the frequency of in-person meetings with their children, the lower the incidence of depression among OALAWAS in rural areas;

Hypothesis $2 \mathbf{2} 2$ (H2a2). The higher the frequency of contact by phone or email, etc., with their children, the lower the incidence of depression among OALAWAS in rural areas; 
Hypothesis $\mathbf{2 b} \mathbf{( H 2 b ) . ~ C h i l d r e n ' s ~ f r e q u e n c y ~ o f ~ c o n t a c t ~ c a n ~ r e d u c e ~ d e p r e s s i o n ~ a m o n g ~ O A L A W A S ~}$ in urban areas;

Hypothesis $\mathbf{2 b 1} \mathbf{( H 2 b 1 ) . ~ T h e ~ h i g h e r ~ t h e ~ f r e q u e n c y ~ o f ~ i n - p e r s o n ~ m e e t i n g s ~ w i t h ~ t h e i r ~ c h i l d r e n , ~ t h e ~}$ lower the incidence of depression among OALAWAS in urban areas;

Hypothesis $\mathbf{2 b 2}$ (H2b2). The higher the frequency of contact by phone or email, etc., with their children, the lower the incidence of depression among OALAWAS in urban areas.

The hierarchy of needs theory divides human needs into physiological needs, safety needs, belonging and love needs, self-esteem needs, and self-actualization needs. According to this theory, people's needs increase incrementally. After their low-level needs are satisfied, people have higher-level needs [53]. With an improvement in their living conditions, high-level emotional needs and respect needs become more important to OALAWAS. Therefore, children's frequency of contact has a greater impact on depression among OALAWAS than their financial support. Due to significant urban-rural differences, the living standards of rural OALAWAS are still lower than those of urban OALAWAS. Therefore, we infer that rural OALAWAS prefer financial support more than urban OALAWAS. Based on the above analysis, we propose the following hypotheses:

Hypothesis 3 (H3). Compared with financial support, children's frequency of contact is more effective at relieving depression among OALAWAS.

Hypothesis 3a (H3a). Compared with financial support, children's frequency of contact is more effective at relieving depression among OALAWAS in rural areas.

Hypothesis $\mathbf{3 b} \mathbf{( H 3 b ) . ~ C o m p a r e d ~ w i t h ~ f i n a n c i a l ~ s u p p o r t , ~ c h i l d r e n ' s ~ f r e q u e n c y ~ o f ~ c o n t a c t ~ i s ~ m o r e ~}$ effective at relieving depression among OALAWAS in urban areas.

Hypothesis 4a (H4a). Compared with OALAWAS in rural areas, children's frequency of contact is more effective at relieving depression among OALAWAS in urban areas.

Hypothesis $\mathbf{4 b} \mathbf{( H 4 b )}$. Compared with OALAWAS in urban, children's financial support is more effective at relieving depression among OALAWAS in rural areas.

\subsection{Sample \\ Data Sources}

The data analyzed in our study were taken from the 2015 China Health and Retirement Longitudinal Study (CHARLS), which is an authority survey of 23,000 respondents from 28 provinces, including urban and rural areas of China. As a longitudinal database, the baseline national wave of CHARLS was fielded in 2011 and individuals are followed up every two years. We chose only the dataset from the 2015 wave because of the following reasons: First, the content of the CHARLS questionnaire is adjusted for changes over time. Therefore, there are slight differences between the datasets from different waves. In our research, we needed to distinguish whether the residents lived in cities or rural areas. However, the questions from the 2013 wave with regard to the urban or rural addresses of residents were not consistent with those of 2015. Compared with the data collected in 2011 and 2013, the data from the 2015 wave contain more detailed information, which is what we required. Second, China's pension insurance has undergone some adjustments since 2014. The rural pension was gradually withdrawn, and China began to implement a unified pension insurance system for urban and rural residents. However, in our study, we need to calculate the residents' pension insurance as a controlled variable. Therefore, we used the latest 2015 data, which is in line with the reality and contains more information.

According to the definition of older adults, we extracted the people whose ages were equal to or over 60 years old $(\geq 60)$. In addition, we also took living conditions into account. 
Only older adults living alone or with a spouse were chosen for the analysis. There were 3886 effective observations that met the criteria, with 3033 OALAWAS in rural areas and 853 in urban areas. Table 1 presents the characteristics of the analytical sample.

Table 1. Descriptive statistics of the analytical sample.

\begin{tabular}{|c|c|c|c|c|c|c|c|c|}
\hline Variable & Min & Max & Mean & SD & Min & Max & Mean & SD \\
\hline & \multicolumn{4}{|c|}{ Urban } & \multicolumn{4}{|c|}{ Rural Area } \\
\hline Depression & 8 & 40 & 17.006 & 6.035 & 1 & 40 & 18.873 & 6.778 \\
\hline Financial support (yuan) & 0 & 750,000 & 7196.423 & $27,363.68$ & 0 & 183,400 & 5401.23 & 9616.827 \\
\hline Frequency of contact (in-person meeting) & 1 & 64 & 11.468 & 9.396 & 0 & 66 & 17.048 & 10.153 \\
\hline Frequency of contact (phone, text, email, etc.) & 0 & 56 & 7.206 & 9.388 & 0 & 80 & 12.901 & 10.845 \\
\hline Educational level & 1 & 10 & 4.238 & 2.107 & 1 & 9 & 2.782 & 1.673 \\
\hline Gender & 0 & 1 & 0.435 & 0.496 & 0 & 1 & 0.399 & 0.49 \\
\hline Marital status & 0 & 1 & 0.824 & 0.381 & 0 & 1 & 0.793 & 0.406 \\
\hline Pain & 0 & 1 & 0.238 & 0.426 & 0 & 1 & 0.355 & 0.479 \\
\hline Self-rated health & 1 & 5 & 3.371 & 0.82 & 1 & 9 & 3.547 & 0.853 \\
\hline Age & 60 & 93 & 68.773 & 6.762 & 60 & 93 & 68.446 & 6.552 \\
\hline Richness of social activities & 0 & 9 & 1.14 & 1.274 & 0 & 8 & 0.724 & 0.931 \\
\hline Frequency of social activities & 0 & 22 & 2.171 & 2.743 & 0 & 21 & 1.482 & 2.177 \\
\hline Personal income(yuan) & 0 & 325,000 & $14,653.61$ & $21,797.05$ & 0 & 136,090 & 2725.373 & 7658.032 \\
\hline
\end{tabular}

\subsection{Measures}

\subsubsection{Dependent Variables: Depression}

In CHARLS, the CESD-10 (with ten items) is used to measure depression. The respondents are asked how they felt and behaved during the last week on a 4-point scale ( 1 = rarely or none of the time, 2 = some or a little of the time, $3=$ occasionally or a moderate amount of the time, $4=$ most or all of the time). Positive questions are assigned in opposite directions. We use higher scores to indicate a higher level of depression.

\subsubsection{Independent Variables: Children's Support}

Financial support means the receipt of economic assistance, including cash support, and in-kind transfers from their children in the past year. Money (support with living expenses, water and electricity fees, telephone rates, etc.) received from their children is added up and referred to as cash support. In-kind support (support with food, clothes, etc.) is converted in monetary terms (in RMB yuan). We summarize the two forms of support, indicated in yuan, as the financial support provided by their children.

We use two indicators to represent the frequency of contact, in line with the procedures carried out in various other studies [34-38]. All respondents are asked to answer two questions. The first asks how often they meet their non-cohabiting children. The other asks how often they have contact with their children via telephone, text message, mail, email, or other methods. Frequency of contact for each question is scored on a 10-point scale ( 1 = almost every day, $2=2-3$ times a week, $3=$ once a week, $4=$ once every two weeks, $5=$ once every month, $6=$ once every three months, $7=$ once every six months, $8=$ once a year, $9=$ almost never, $10=$ other). We add up the score and take the reciprocal to measure the level of frequency of contact.

\subsubsection{Control Variables}

Based on the existing studies, we consider the demographic characteristics, physical health, socioeconomic status, and social characteristic as the control variables in the analysis. The demographic characteristics include age, gender $(1=$ female, $0=$ male $)$ and marital status ( $1=$ spouse, $0=$ no spouse). Participants' physical health status is evaluated by their self-rated health $(1=$ very good, $2=$ good, $3=$ fair, $4=$ poor, $5=$ very poor $)$ and pain $(1=$ pain, $0=$ no pain). For self-rated health, we add up the scores and then take the reciprocal to measure the participants' personal health. A higher score means a better 
self-rated health level. Participants' socioeconomic status is indicated by their income and education levels. Their income is the sum of their pension and government transfer income. Participants' education level is measured by the number of years of education they received, with high values meaning a high education level. We use the participants ${ }^{\prime}$ richness and frequency of social activities to measure their level of participation in social activities. To assess the richness of their social activities, people were asked to select from eleven types of social activities, including sports, entertainment, community activities, etc. The richness of social activities is the sum of the types of social activities participants engage in; higher values mean richer/broader categories of social activities. The frequency of social activities is the frequency at which participants have engaged in social activities in the past month ( 1 = almost daily, 2 = almost every week, $3=$ not regularly). We sum the scores to measure the frequency of personal social activity; higher scores indicate a lower frequency of personal social activities.

\subsubsection{Analytic Strategy}

All statistical analyses were conducted using Stata 15 . The first step involves a descriptive statistical analysis. Through this analysis, we can obtain basic information about OALAWAS in China, especially the distribution of depression in three dimensions (country, urban and rural areas). The second step is the regression analysis. We use Pearson correlation coefficients to detect the relationships between the variables, and the variance inflation factor (VIF) to determine whether there is collinearity between the independent variables. On this basis, we use multiple linear regression to analyze the relationship between children's support and depression among OALAWAS. Based on the regression results, we conduct a comparative analysis of urban and rural areas.

\section{Results}

\subsection{Descriptive Analysis}

The average age of OALAWAS in China is 68 years old. The results show that the average depression level of OALAWAS in rural areas is 18.873, higher than that in urban areas. Urban OALAWAS receive 7196 yuan on average in terms of financial assistance, while the average amount in rural areas is 5401 yuan. The average scores for the frequency of contact show that OALAWAS in rural areas have a higher frequency of contact with their children than those in urban areas, in the form of more frequent in-person meetings and contact by phone or other methods. The educational level, personal income, richness, and frequency of social activities of urban OALAWAS are higher than those of rural OALAWAS.

\subsection{Multiple Regression Analysis}

Based on the correlation analysis, we found that there was a correlation between the independent variable and the dependent variables. The maximum value of the VIF was less than 10, indicating that there was no obvious collinearity. When controlling for the effects of the demographic characteristics, socioeconomic status, physical health, and social characteristics, which are proven to be determinants of depression, we conducted a multiple regression analysis to explore the effect of children's support on depression among OALAWAS. The results are shown in Table 2.

In Model 1, we found that OALAWAS in rural areas are more prone to suffering from depression than those in urban areas. From a national perspective, children's financial support and frequency of contact are both protective factors for reducing depression among OALAWAS $(p<0.01)$, in support of $\mathrm{H} 1$ and $\mathrm{H} 2$. By comparing the coefficient values of financial support and frequency of contact, we found that the regression result confirmed that children's frequency of contact has a greater effect on relieving depression among OALAWAS, in support of H3. Variables such as age, education, self-rated health and richness and frequency of social activities are negatively correlated with depression among OALAWAS. This indicates that improving older adults' personal education, health and social activities could effectively reduce the risk of depression. OALAWAS who are female, 
with no spouse, and who suffer from pain are more prone to experiencing depression $(p<0.01)$. In addition, a lower frequency of social activities leads to a higher depression level among OALAWAS.

Table 2. Results of multiple regression analysis.

\begin{tabular}{|c|c|c|c|}
\hline Variable & Model 1 & Model 2 & Model 3 \\
\hline & Total & Rural Areas & Urban \\
\hline $\begin{array}{l}\text { Living address } \\
\text { (Rural as reference) }\end{array}$ & $\begin{array}{c}-0.421 \\
(-1.65) *\end{array}$ & & \\
\hline Financial support & $\begin{array}{c}-0.119 \\
(-3.71) * * *\end{array}$ & $\begin{array}{c}-0.123 \\
(-3.05)^{* * * *}\end{array}$ & $\begin{array}{c}-0.119 \\
(-2.31)^{* *}\end{array}$ \\
\hline Frequency of contact (in-person meeting) & $\begin{array}{l}-1.630 \\
(-2.63) * * *\end{array}$ & $\begin{array}{c}-2.434 \\
(-2.88)^{* * * *}\end{array}$ & $\begin{array}{l}-0.289 \\
(-0.33)\end{array}$ \\
\hline Frequency of contact (phone, text, email, etc.) & $\begin{array}{c}-1.643 \\
(-2.86)^{* * *}\end{array}$ & $\begin{array}{c}-1.936 \\
(-2.65)^{* * * *}\end{array}$ & $\begin{array}{l}-0.783 \\
(-0.87)\end{array}$ \\
\hline Educational level & $\begin{array}{c}-0.179 \\
(-3.04)^{* * * *}\end{array}$ & $\begin{array}{c}-0.218 \\
(-3.00)^{* * * *}\end{array}$ & $\begin{array}{l}-0.0932 \\
(-0.96)\end{array}$ \\
\hline Gender & $\begin{array}{c}1.258 \\
(6.03)^{* * * *}\end{array}$ & $\begin{array}{c}1.423 \\
(5.79)^{* * * *}\end{array}$ & $\begin{array}{l}0.483 \\
(1.24)\end{array}$ \\
\hline Marital status & $\begin{array}{c}-1.203 \\
(-4.77) * * *\end{array}$ & $\begin{array}{c}-1.264 \\
(-4.38)^{* * * *}\end{array}$ & $\begin{array}{l}-0.773 \\
(-1.49)\end{array}$ \\
\hline Pain & $\begin{array}{c}4.858 \\
(23.23)^{* * *}\end{array}$ & $\begin{array}{c}4.871 \\
(20.64)^{* * *}\end{array}$ & $\begin{array}{c}4.741 \\
(10.47)^{* * *}\end{array}$ \\
\hline Self-rated health & $\begin{array}{c}-10.31 \\
(-12.63)^{* * *}\end{array}$ & $\begin{array}{c}-9.702 \\
(-10.33) * * *\end{array}$ & $\begin{array}{c}-12.64 \\
(-7.73)^{* * *}\end{array}$ \\
\hline Age & $\begin{array}{c}-0.0825 \\
(-5.40)^{* * *}\end{array}$ & $\begin{array}{c}-0.0895 \\
(-4.99)^{* * *}\end{array}$ & $\begin{array}{l}-0.0542 \\
(-1.85)^{*}\end{array}$ \\
\hline Richness of social activities & $\begin{array}{c}-0.648 \\
(-2.76)^{* * *}\end{array}$ & $\begin{array}{l}-0.732 \\
(-2.43)^{* *}\end{array}$ & $\begin{array}{l}-0.525 \\
(-1.47)\end{array}$ \\
\hline Frequency of social activities & $\begin{array}{c}0.209 \\
(2.04)^{* *}\end{array}$ & $\begin{array}{c}0.246 \\
(1.91)^{*}\end{array}$ & $\begin{array}{l}0.120 \\
(0.74)\end{array}$ \\
\hline Personal income & $\begin{array}{l}0.0000164 \\
(-2.06)^{* *}\end{array}$ & $\begin{array}{l}-0.0000360 \\
(-2.49)^{* *}\end{array}$ & $\begin{array}{c}0.0000123 \\
(-1.36)\end{array}$ \\
\hline _cons & $\begin{array}{c}28.34 \\
(22.72)^{* * *}\end{array}$ & $\begin{array}{c}28.91 \\
(19.64)^{* * * *}\end{array}$ & $\begin{array}{c}25.97 \\
(10.81)^{* * *}\end{array}$ \\
\hline$N$ & 3886 & 3033 & 853 \\
\hline$R^{2}$ & 0.260 & 0.250 & 0.269 \\
\hline
\end{tabular}

Model 2 testified that both children's financial support and frequency of contact have a positive impact on the depression level of OALAWAS in rural areas, in support of H1a and H2a at a statistical level of 1\%. Compared with financial support, children's frequency of contact has a greater relieving effect on depression. Additionally, the effect of children's face to face visits (H3a and H2a) on reducing depression is better than that of contact via telephone, text message, or other means. Influencing factors such as age, education, and self-rated health are still significant protective factors for depression among OALAWAS. Older people who live in rural areas, who are female, who have no spouse and who suffer from pain are more prone to depression $(p<0.01)$. In rural areas of China, a higher frequency of social activities and a richer diversity of social activities have more ameliorating effects on depression among OALAWAS. Higher income also helps to relieve depression among OALAWAS in rural China.

In Model 3, the results show that children's financial support has a significant positive effect on the depression levels of OALAWAS in urban areas, confirming the assumption of $\mathrm{H} 1 \mathrm{~b}(p<0.05)$. Contrary to the results, with regard to rural areas, frequency of contact from children in urban areas did not pass the statistical test, which means that this variable fails to support hypotheses $\mathrm{H} 2 \mathrm{~b}$ and $\mathrm{H} 3 \mathrm{~b}$. Among the control variables, physical condition is the most effective factor contributing to the incidence of depression. 
The comparative analysis of Model 2 and Model 3 shows that children's financial support has a more significant impact on depression among OALAWAS in rural areas than in urban areas (H4b). However, children's frequency of contact has no significant effect on depression among OALAWAS in urban areas, rejecting the hypothesis of H4a. In contrast, children's support may more easily influence the psychological state of OALAWAS in rural areas than in urban regions. Physical condition passed the significance test in both Model 2 and Model 3. This means that physical condition plays an important role in the psychological health of OALAWAS both in urban and rural areas. Social activities, which play an important role in alleviating depression among OALAWAS in rural China, did not pass the statistical test in the urban regression. Personal income, which is significant in rural model, did not pass the statistical test in the urban regression.

\subsection{Marginal Effects}

Furthermore, we compare the marginal effects of different influencing factors of depression. The results are shown in Figure 2. The coefficients of regression in rural areas show that self-rated health, physical pain, and in-person meetings are the top three influencing factors of depression among OALAWAS in rural areas. As for frequency of contact, this turns out to be more effective at reducing depression than demographic factors in the rural model. Self-rated health, pain, and financial support are the top three factors affecting depression among OALAWAS in urban areas. The effect of self-rated health on depression in urban areas is stronger than that in rural areas. Social activities, which are important determinants in the rural model, do not have an effect on depression among OALAWAS in the urban model.

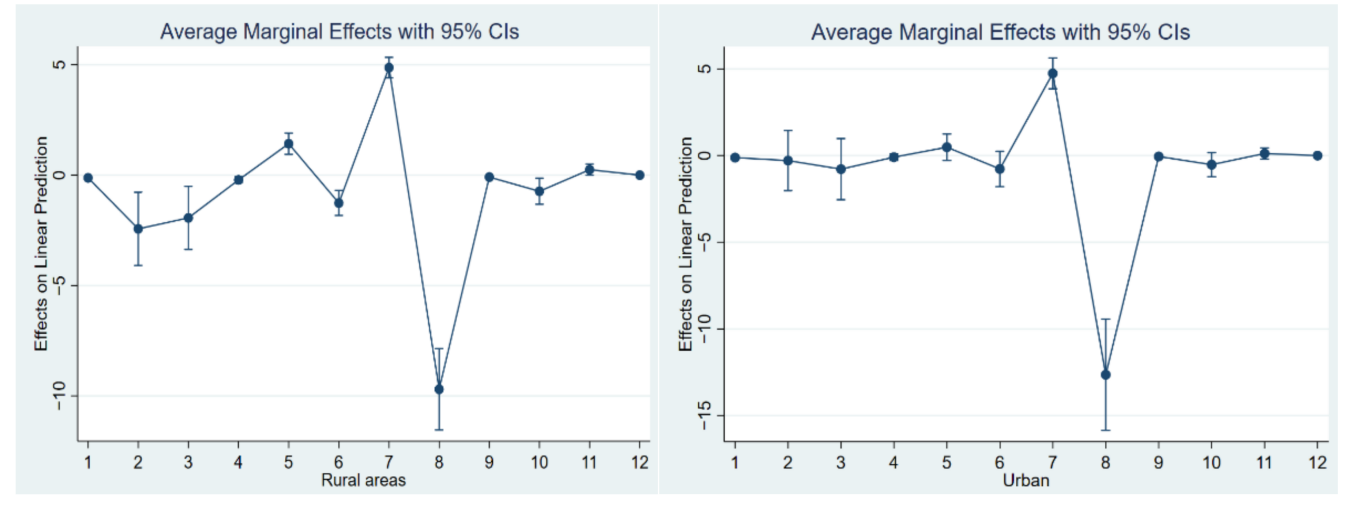

Figure 2. Marginal effects of influencing factors in urban and rural areas: 1: financial support; 2: frequency of contact via in-person meetings; 3: frequency of contact by phone/email, etc.; 4 : educational level; 5: gender; 6: marital status; 7: pain; 8: self-rated health; 9: age; 10: richness of social activities; 11: frequency of social activities; 12: personal income.

\section{Discussion}

\subsection{Analysis of Children's Frequency of Contact}

The results show that children's frequency of contact is effective at relieving depression among OALAWAS in rural areas, and this is consistent with other studies [17,32,34,38,41]. However, for OALAWAS in urban areas, children's frequency of contact plays no role in relieving depression. There are two possible explanations for these differing results.

First, the needs of older adults are changing over time. With the rapid development of the economy in China, the living standards of older adults are continuously improving. After their basic needs are satisfied, their higher-level needs, including emotion, respect, and self-actualization, are more important. Financial support may no longer be as important as frequency of contact in terms of affecting the mental health of OALAWAS in rural areas. Children's frequency of contact could promote emotional communication and reduce anxiety among OALAWAS, bringing benefits due to a mutual understanding. Moreover, in-person meetings with children are better than contact with children by telephone or other 
methods in terms of reducing the risk of depression. This is probably because face-to-face contact is more real and is often accompanied by life care and instrumental support from children [50].

Secondly, there are vast differences between urban and rural areas in the construction of cultural and recreational facilities. In urban areas, local governments provide hierarchical cultural facilities that integrate the functions of culture, sports, leisure, and entertainment, covering living districts, streets, and communities. For OALAWAS in urban areas, public cultural and recreational facilities can enrich their lives and reduce their loneliness. Even if there is little contact with their children, they may still have adequate ways in which to enrich their lives. However, weak infrastructure and a reduced number of cultural activities lead to loneliness among older adults in rural areas [54], as they have few emotional outlets. In addition, rapid urbanization in China has caused the migration of young people from rural to urban areas, meaning that older adults are geographically separated from their adult children. This geographical separation deepens their demand for emotional contact with their children.

\subsection{Analysis of Children's Financial Support}

Children's financial support can reduce depression levels among older adults, no matter where they live. This result is consistent with previous research $[6,38]$. From the urban-rural disparity perspective, we found that children's financial support has a more significant effect on relieving depression among OALAWAS in rural areas than in urban areas. However, other studies suggest that obtaining financial support from children increases depression among older adults [21,41]. This inconsistency is attributable to differences in data sources. Based on national survey data, some researchers have concluded that there is a negative correlation between children's financial support and older adults' depression levels; however, when using regional questionnaire data, some studies reach the opposite conclusion $[6,21,38,41]$. Moreover, the definition and measurement of financial support also affect the results. This study considers the amount of financial support provided, while some studies only considered whether financial support existed or not. Our explanation of the financial support results are as follows:

First, family support, especially children's support, is an important part of the social support system for OALAWAS in China. Children are responsible for their parents' lives as a manifestation of filial piety, and older adults can gain a sense of satisfaction and feel pride for their children when they feel supported by them. Financial support from children could help OALAWAS to maintain a positive attitude, avoid mental illness, and reduce the possibility of depression.

Secondly, the main sources of income for OALAWAS are different between urban and rural areas. One study shows that $50.12 \%$ of older adults live on their pensions in urban areas, with $31.36 \%$ being mainly supported by their family members. For older adults in rural areas, only $4.6 \%$ of them have a retirement pension, while $47.74 \%$ rely on family members' financial support [55]. OALAWAS living in rural areas generally do not have formal jobs, relying instead on agricultural work for their income. Due to the decline in physical function with age, they may find it difficult to engage in agricultural work. In the absence of a pension or agricultural income, older adults in rural China mainly depend on their children's support. That is the reason why the economic assistance of their children plays a greater role in older adults' psychological health in rural areas than in urban areas.

Thirdly, the urban-rural disparity in China's social security system is profound. Since the reform and opening up, China's social security system has been gradually improved, but the gaps and scope of security in different regions vary greatly [56-58]. This impairs the fairness and efficiency of the social security system and leads to the unfair distribution of welfare provisions between urban and rural residents [59]. Therefore, older adults in rural areas rely more on their children's financial support. 


\subsection{Contributions and Limitations}

This study contributes to the research on OALAWAS, who comprise a vulnerable group that deserves more attention in Chinese society. In addition, the use of national questionnaire survey data could make the analyzed sample more authoritative and representative. In our comparative analysis, we revealed the impact and disparity of children's support on depression among OALAWAS in urban and rural areas. This could benefit the formulation of targeted public policies for governors when faced with complex situations in relation to OALAWAS in urban vs. rural areas.

This research also has some limitations that require further improvements to be made. Firstly, the regional disparities between eastern, middle, and western China are not discussed. In this study, we only consider the differences between urban and rural areas, while regional differences between eastern, middle, and western China do not form part of the analysis. Secondly, support from children of different genders may have different effects on depression levels, because OALAWAS may have different expectations for their daughters and sons. In addition, the discrepancy between what is needed and what is received could also have an influence on the depression levels among OALAWAS, which requires further exploration in future studies. Thirdly, due to data limitations, this study did not calculate the effects of life care and instrumental support. Even though there is a highly positive correlation between life care/instrumental support and in-person contact, only in-person contact is included in the analysis described in this paper. It would be better if particular questions and data, specifically designed with life care and instrumental support from children in mind, could be collected and explored in future research.

\section{Conclusions}

China is preparing for the challenges that will come with its aging population, and OALAWAS, as a vulnerable group, deserve more attention. Based on data from the China Health and Retirement Longitudinal Study, this article studies the effect of children's support on depression among OALAWAS, from the perspective of urban-rural disparities. For OALAWAS in rural areas, children's financial support and frequency of contact can significantly reduce the risk of depression. Compared with financial support, increasing the frequency of contact with their children has a stronger effect on relieving depression among OALAWAS in rural areas. In-person meetings perform better at reducing depression than indirect contact, such as via telephone, text, email, etc. For OALAWAS in urban areas, their children's financial support has a significant effect on relieving their depression, while children's frequency of contact is not significant. Our research reveals the effect and disparity of children's support on depression among OALAWAS, and we hope that it will benefit decision makers when formulating targeted policies in this regard.

Author Contributions: Conceptualization, X.R. and C.L.; methodology, X.R.; software, X.R.; validation, X.R.; formal analysis, X.R.; investigation, X.R.; resources, X.R.; data curation, X.R.; writingoriginal draft preparation, X.R.; writing-review and editing, X.R. and C.L.; visualization, X.R.; supervision, C.L.; project administration, C.L.; funding acquisition, C.L. All authors have read and agreed to the published version of the manuscript.

Funding: This research was funded by the National Natural Science Foundation of China (41671124) and the University of Chinese Academy of Sciences (Y95402CXX2).

Institutional Review Board Statement: Not applicable.

Informed Consent Statement: Not applicable.

Data Availability Statement: The data we used in our study is called "China Health and Retirement Longitudinal Study, CHARLS", and it is available at http:/ / charls.pku.edu.cn/ (accessed on 20 May 2021).

Acknowledgments: Thanks are due to the CHARLS study for sharing their data with us. The authors are very grateful for the valuable comments and suggestion of the anonymous reviewers. 
Conflicts of Interest: The authors declare that there are no conflict of interest.

\section{References}

1. Peng, X.Z.; Hu, Z. China's population aging from the perspective of public policy. Soc. Sci. China 2011, 32, 106-124.

2. Wu, X.L.; Li, J.; Wang, L.L. Analysis on the depressive symptoms of elderly in China. Popul. J. 2010, 5, 43-47.

3. Yang, G. The impact of social transformation on family structure and intergenerational residence model:Data from Shanghai, Zhejiang and Fujian province. Popul. J. 2017, 39, 5-17.

4. Chen, Y. Comparison of the health status, social support and quality of life between the elderly living alone and not living alone in Shanghai. Chin. J. Gerontol. 2017, 37, 6211-6214.

5. Zhang, W.J.; Li, S.Z. Research on the influence of children's intergenerational support behavior on the life satisfaction of rural elderly. Popul. Res. 2005, 29, 73-80.

6. Wang, P.; Huang, L.P.; Cao, X.M.; Wang, Z.W.; Fang, F.; Zhou, X.M. The effects of psychological intervention in the elderly solitary people with depression. J. Clin. Psychiatry 2017, 27, 108-110.

7. Fiske, A.; Wetherell, J.L.; Gatz, M. Depression in older adults. Annu. Rev. Clin. Psychol. 2009, 5, 363-389. [CrossRef]

8. Pimouguet, C.; Rizzuto, D.; Schon, P.; Shakersain, B.; Angleman, S.; Lagergren, M.; Fratiglioni, L.; Xu, W. Impact of living alone on institutionalization and mortality: A population-based longitudinal study. Eur. J. Public Health 2016, 26, 182-187. [CrossRef]

9. Tong, H.M.; Lai, D.W.L.; Zeng, Q.; Xu, W.Y. Effects of social exclusion on depressive symptoms: Elderly chinese living alone in Shanghai, China. J. Cross-Cult. Gerontol. 2011, 26, 349-364. [CrossRef]

10. Lim, L.L.; Kua, E.-H. Living alone, loneliness, and psychological well-being of older persons in Singapore. Curr. Gerontol. Geriatr. Res. 2011, 2011, 673181. [CrossRef]

11. Li, J.; Ma, W. Prevalence and influencing factors of depression symptom among middle-aged and elderly people in China. China J. Public Health 2017, 33, 177-181.

12. Judd, L.L.; Schettler, P.J.; Akiskal, H.S. The prevalence, clinical relevance, and public health significance of subthreshold depressions. Psychiatr. Clin. N. Am. 2002, 25, 685-698. [CrossRef]

13. Van de Velde, S.; Bracke, P.; Levecque, K. Gender differences in depression in 23 European countries. Cross-national variation in the gender gap in depression. Soc. Sci. Med. 2010, 71, 305-313. [CrossRef]

14. Do, Y.K.; Malhotra, C. The effect of coresidence with an adult child on depressive symptoms among older widowed women in South Korea: An instrumental variables estimation. J. Gerontol. B-Psychol. 2012, 67, 384-391. [CrossRef] [PubMed]

15. Recksiedler, C.; Stawski, R.S. Marital transitions and depressive symptoms among older adults: Examining educational differences Gerontology 2019, 65, 407-418. [CrossRef]

16. Kim, K.; Lee, M. Depressive symptoms of older adults living alone: The role of community characteristics. Int. J. Aging Hum. Dev. 2015, 80, 248-263. [CrossRef] [PubMed]

17. Li, C.; Jiang, S.; Zhang, X. Intergenerational relationship, family social support, and depression among chinese elderly: A structural equation modeling analysis. J. Affect. Disord. 2019, 248, 73-80. [CrossRef]

18. Sibalija, J.; Savundranayagam, M.Y.; Orange, J.B.; Kloseck, M. Social support, social participation, \& depression among caregivers and non-caregivers in Canada: A population health perspective. Aging Ment. Health 2020, 24, 765-773.

19. Qin, J. The predicament of the elderly living alone in the elderly in rural areas and its solution: From the perspective of social support network theory. Soc. Sci. Hunan 2013, 26, 109-112.

20. Gariepy, G.; Honkaniemi, H.; Quesnel-Vallee, A. Social support and protection from depression: Systematic review of current findings in Western countries. Br. J. Psychiatry 2016, 209, 286-295. [CrossRef] [PubMed]

21. Zimmer, Z.; Kwong, J. Family size and support of older adults in urban and rural China: Current effects and future implications Demography 2003, 40, 23-44. [CrossRef] [PubMed]

22. Chou, K.L.; Ho, A.H.Y.; Chi, I. Living alone and depression in chinese older adults. Aging Ment. Health 2006, 10, 583-591. [CrossRef]

23. Zhou, Z.; Mao, F.; Ma, J.; Hao, S.; Qian, Z.; Elder, K.; Turner, J.S.; Fang, Y. A longitudinal analysis of the association between living arrangements and health among older adults in China. Res. Aging 2018, 40, 72-97. [CrossRef] [PubMed]

24. Yuan, Z.-q.; Zheng, X.; Hui, E.C.M. Happiness under one roof? The intergenerational co-residence and subjective well-being of elders in China. J. Happiness Stud. 2021, 22, 727-765. [CrossRef]

25. Tang, D.; Lin, Z.; Chen, F. Moving beyond living arrangements: The role of family and friendship ties in promoting mental health for urban and rural older adults in China. Aging Ment. Health 2020, 24, 1523-1532. [CrossRef]

26. So, W.K.W.; Chan, H.Y.L.; Wong, M.M.H.; Choi, K.C.; Cheung, R.K.Y.; Sit, J.W.H.; Ho, B.; Li, F.Y.K.; Lee, T.Y.; Chair, S.Y. Risks of malnutrition and depression in older adults living alone or with a spouse in Hong Kong. Psychogeriatrics 2020, 20, 936-940. [CrossRef]

27. Kim, S.J.; Shin, I.S.; Shin, H.Y.; Kim, J.M.; Kim, S.W.; Yoon, J.S. Comparison of depression between the elderly living alone and those living with a spouse. J. Korean Soc. Biol. Ther. Psychiatry 2015, 21, 192-198.

28. Fukunaga, R.; Abe, Y.; Nakagawa, Y.; Koyama, A.; Fujise, N.; Ikeda, M. Living alone is associated with depression among the elderly in a rural community in Japan. Psychogeriatrics 2012, 12, 179-185. [CrossRef]

29. Stahl, S.T.; Beach, S.R.; Musa, D.; Schulz, R. Living alone and depression: The modifying role of the perceived neighborhood environment. Aging Ment. Health 2017, 21, 1065-1071. [CrossRef] 
30. Tian, Q. Intergeneration social support affects the subjective well-being of the elderly: Mediator roles of self-esteem and loneliness. J. Health Psychol. 2016, 21, 1137-1144. [CrossRef]

31. Cong, Z.; Silverstein, M. Parents' depressive symptoms and support from sons and daughters in rural China. Int. J. Soc. Welf. 2011, 20, S4-S17. [CrossRef] [PubMed]

32. Guo, M.; Chi, I.; Silverstein, M. Intergenerational support and depression among chinese older adults: Do gender and widowhood make a difference? Ageing Soc. 2017, 37, 695-724. [CrossRef]

33. Tosi, M.; Grundy, E. Intergenerational contacts and depressive symptoms among older parents in Eastern Europe. Aging Ment. Health 2019, 23, 686-692. [CrossRef]

34. Roh, H.W.; Lee, Y.; Lee, K.S.; Chang, K.J.; Kim, J.; Lee, S.J.; Back, J.H.; Chung, Y.K.; Lim, K.Y.; Noh, J.S.; et al. Frequency of contact with non-cohabitating adult children and risk of depression in elderly: A community-based three-year longitudinal study in Korea. Arch. Gerontol. Geriat. 2015, 60, 183-189. [CrossRef]

35. $\mathrm{Wu}, \mathrm{F}$. Intergenerational support and life satisfaction of older parents in China: A rural-urban divide. Soc. Indic. Res. 2021. [CrossRef]

36. Fu, L.; Wang, Y.; He, L. Factors associated with the psychological health of caregiving older parents and support from their grown children: Results from the China health and retirement longitudinal study. Int. J. Environ. Res. Public Health 2020, 17, 556. [CrossRef]

37. $\mathrm{Xu}, \mathrm{H}$. Physical and mental health of chinese grandparents caring for grandchildren and great-grandparents. Soc. Sci. Med. 2019, 229, 106-116. [CrossRef]

38. Tao, Y.C.; Shen, Y. The influence of social support on the physical and mental health of the rural elderly. Popul. Econ. 2014, 3, 3-14.

39. Jia, Y.-H.; Ye, Z.-H. Impress of intergenerational emotional support on the depression in non-cohabiting parents. World J. Clin. Cases 2019, 7, 3407-3418. [CrossRef]

40. Lee, H.J.; Lyu, J.; Lee, C.M.; Burr, J.A. Intergenerational financial exchange and the psychological well-being of older adults in the republic of Korea. Aging Ment. Health 2014, 18, 30-39. [CrossRef]

41. Liu, H.; Li, Q.; Xue, X.L. Influence of two-way inter-generational support on the physical and mental health of the rural elderly: Based on the survey data of Shandong province. J. Hunan Agric. Univ. 2019, 20, 49-56.

42. Silverstein, M.; Cong, Z.; Li, S. Intergenerational transfers and living arrangements of older people in rural China: Consequences for psychological well-being. J. Gerontol. B-Psychol. 2006, 61, S256-S266. [CrossRef]

43. Cong, Z.; Silverstein, M. Caring for grandchildren and intergenerational support in rural China: A gendered extended family perspective. Ageing Soc. 2012, 32, 425-450. [CrossRef]

44. Djundeva, M.; Mills, M.; Wittek, R.; Steverink, N. Receiving instrumental support in late parent-child relationships and parental depression. J.Gerontol. B-Psychol. 2015, 70, 981-994. [CrossRef]

45. Roll, A.; Litwin, H. Intergenerational financial transfers and mental health: An analysis using share-israel data. Aging Ment. Health 2010, 14, 203-210. [CrossRef]

46. Wang, P.; Zhang, W.J.; Wang, J. Influence of family intergenerational support on mental health of rural elderly. Chin. J. Gerontol. 2017, 37, 4893-4896.

47. Musil, C.M.; Gordon, N.L.; Warner, C.B.; Zauszniewski, J.A.; Standing, T.; Wykle, M. Grandmothers and caregiving to grandchildren: Continuity, change, and outcomes over 24 months. Gerontologist 2011, 51, 86-100. [CrossRef]

48. Tang, D. The mediating effect of urban and rural residence in the model of depression among chinese elderly. Popul. Res. 2010, 34, 53-63.

49. Chen, Y.; Hicks, A.; While, A.E. Loneliness and social support of older people in China: A systematic literature review. Health Soc. Care Community 2014, 22, 113-123. [CrossRef]

50. Li, M.; Luo, Y.; Li, P. Intergenerational solidarity and life satisfaction among empty-nest older adults in rural China: Does distance matter? J. Fam. Issues 2021, 42, 626-649. [CrossRef]

51. Thanakwang, K. Family support, anticipated support, negative interaction, and psychological well-being of older parents in Thailand. Psychogeriatrics 2015, 15, 171-178. [CrossRef] [PubMed]

52. Ikkink, K.K.; van Tilburg, T.; Knipscheer, K. Perceived instrumental support exchanges in relationships between elderly parents and their adult children: Normative and structural explanations. J. Marriage Fam. 1999, 61, 831-844. [CrossRef]

53. Hagerty, M.R. Testing maslow's hierarchy of needs: National quality-of-life across time. Soc. Indic. Res. 1999, 46, $249-271$. [CrossRef]

54. Wang, J.X.; Huang, Y.L.; Wu, G.S.; Fu, C.W.; Xu, X.J.; Wu, L.C. On current chinese rural culture construction. J. Cent. China Norm. Univ. 2007, 4, 101-111.

55. Lin, M.G.; Liang, Y.; Liu, L.C. A regional comparative study on the pension status of China's elderly population-Based on the analysis of the sixth national census data. J. Wuhan Univ. Sci. Technol. 2014, 16, 204-208.

56. Ding, J.D.; Cao, Y.H. The improvement of China's rural old-age security system from the perspective of the shared development concept-Based on the analysis framework of the "three systems of social security system". Acad. Bimest. 2017, 28, 42-47.

57. Zuo, T.; Zhao, M.Y.; Jin, J. Approaches, mechanism and innovation:policy review on social security system for poverty alleviation. J. Huazhong Agric. Univ. 2018, 1, 1-12. 
58. Wang, L.J.; Dai, X.L. The evolutionary logic and future prospect of China's rural social security system since the founding of new China. Issues Agric. Econ. 2020, 41, 65-76.

59. Zhao, X.F. On the fragmentation of social security from the perspective of procedural justice. Theory Mon. 2012, 34, 128-132. 